\title{
Inhaled nitric oxide as a screening agent for safely identifying responders to oral calcium-channel blockers in primary pulmonary hypertension
}

\author{
O. Sitbon, M. Humbert, J-L. Jagot, O. Taravella, M. Fartoukh, F. Parent, P. Herve, G. Simonneau
}

\begin{abstract}
Inhaled nitric oxide as a screening agent for safely identifying responders to oral calciumchannel blockers in primary pulmonary hypertension. O. Sitbon, M. Humbert, J-L. Jagot, O. Taravella, M. Fartoukh, F. Parent, P. Herve, G. Simonneau. @ERS Journals Ltd 1998.

ABSTRACT: In a subset of patients with primary pulmonary hypertension (PPH), high doses of oral calcium-channel blockers (CCB) produce a sustained clinical and haemodynamic improvement. However, significant side-effects have been reported during acute testing with CCB. Therefore, to identify accurately patients who may benefit from long-term CCB therapy, there is a need for a safe, potent and short-acting vasodilator.

The aim of this study was to compare the acute response to inhaled nitric oxide (NO) and oral high doses of CCB in 33 consecutive patients with PPH. A significant acute vasodilator response was defined by a fall in both mean pulmonary artery pressure and total pulmonary resistance by $>20 \%$.

Ten patients responded acutely to NO, nine of whom responded acutely to $\mathrm{CCB}$, without any complications. The 23 other patients failed to respond to NO and CCB. In these nonresponders, nine serious adverse events were observed with CCB (38\%). There was no clinical or baseline haemodynamic feature predicting acute vasodilator response. Long-term oral treatment with $\mathrm{CCB}$ was restricted to the nine acute responders and a sustained clinical and haemodynamic improvement was observed in only six patients.

In primary pulmonary hypertension, the acute response rate to high doses of calcium-channel blockers is low (27\%). Serious adverse reactions to high doses of calciumchannel blockers during acute testing are frequently observed in nonresponders. It is concluded that nitric oxide may be used as a screening agent for safely identifying patients with primary pulmonary hypertension who respond acutely to calcium-channel blockers and may benefit from long-term treatment with these agents .

Eur Respir J 1998; 12: 265-270.
\end{abstract}

Service de Pneumologie et Réanimation Respiratoire, UPRES Maladies Vasculaires Pulmonaires, Hôpital Antoine Béclère, Université Paris XI, Clamart, France.

Correspondence: O. Sitbon

Service de Pneumologie et Réanimation

157, Avenue de la Porte de Trivaux

92141 Clamart Cedex

France

Fax: 33146303824

Keywords: Calcium-channel blockers nitric oxide

primary pulmonary hypertension

vasodilator challenge

Received: May 261997

Accepted after revision March 131998
Over the past decade, there has been considerable interest in the use of vasodilator agents in the treatment of patients with primary pulmonary hypertension $(\mathrm{PPH})[1$, $2]$. The calcium-channel blockers (CCB) nifedipine and diltiazem are the most widely used drugs for oral longterm treatment in patients with PPH [3]. Recommended doses of CCB in PPH are usually higher than those commonly given in others indications [3]. However, their longterm administration is restricted to a minority of patients who respond acutely to such drugs [4-6]. In addition, a major issue concerns the possible occurrence of severe side-effects during acute vasodilator testing with $\mathrm{CCB}$ in patients with $\mathrm{PPH}$, even when conventional doses are used [7-10]. Therefore, there is a need for a safe, potent and short-acting vasodilator with limited side-effects during acute testing to identify accurately those patients who may benefit from long-term CCB therapy [11-15]. For this purpose, inhaled nitric oxide (NO), a selective pulmonary vasodilator, could be one of the most suitable candidates $[12,16]$. The aim of the present study was to assess whether inhaled NO testing could identify patients with PPH

For editorial comment see page 263 who are likely to respond to high doses of CCB. Thus, the efficacy and safety of inhaled NO and high doses of oral CCB were prospectively compared during acute vasodilator testing in 33 consecutive patients with PPH referred to the authors' centre for therapeutic assessment.

\section{Methods}

\section{Subjects}

Thirty-three consecutive patients with PPH referred to the authors' centre between September 1994 and May 1995 were included in this study. Each patient fulfilled the diagnostic criteria for PPH according to the protocol of the National Institutes of Health Primary Pulmonary Hypertension Registry [17]. Pulmonary hypertension was defined by a mean pulmonary artery pressure $(P$ pa $)>3.3$ $\mathrm{kPa}(25 \mathrm{mmHg})$ at rest with a mean pulmonary artery occlusion pressure ð1.6 $\mathrm{kPa}(12 \mathrm{mmHg})$, during right-side heart catheterization. Secondary causes of pulmonary hypertension, including significant connective tissue disease, 
were excluded on the results of history, physical examination, chest radiography, pulmonary function testing, perfusion lung scan or pulmonary angiography or both, two-dimensional echocardiography and absence of left-toright shunting.

\section{Study design}

A complete initial baseline haemodynamic evaluation was performed in supine patients, while they were breathing room air and after all vasodilating or inotropic agents had been discontinued for at least 36-48 $\mathrm{h}$ before the study. After venous access was achieved through an antecubital or internal jugular vein, catheterization was performed by means of a $7 \mathrm{~F}$ triple lumen flow-directed thermodilution catheter (Baxter Edwards, Irvine, CA, USA) which was advanced into a lower lobar pulmonary artery under fluoroscopic guidance. Transducers were positioned at the midaxillary line and zeroed at atmospheric pressure. Cardiac output (CO) was determined in triplicate with cold dextrose $\left(0-5^{\circ} \mathrm{C}\right)$ by the thermodilution technique (Cardiac Output Computer; Baxter Edwards). Cardiac index (CI) was calculated as $\mathrm{CO}$ divided by body surface area $\left(\mathrm{m}^{2}\right)$. Because the pulmonary artery occlusion pressure could not be consistently recorded in all patients during the entire haemodynamic evaluation, total pulmonary resistance (TPR), instead of pulmonary arterial resistance, was considered and calculated as $P$ pa divided by CI. Cardiac frequency $(f \mathrm{C})$ was monitored continuously and systemic arterial pressure determined intermittently by an automated blood pressure cuff (Dinamap® 1800; Critikon, Tampa, FL, USA). Transcutaneous arterial oxyhaemoglobin saturation was continuously monitored by pulse oximetry (Biox 3700; Ohmeda, Louisville, CO, USA).

After two or three sets of baseline haemodynamic measurements over $90 \mathrm{~min}$, patients were initially tested with a short-term inhalation of an air-NO (10 parts per million (ppm)) mixture administered through a face mask over 6-10 min, as described previously [12]. After acute testing with NO was completed, patients were transferred to the intensive care unit for further evaluation with CCB. The study was conducted according to guidelines provided previously by Rich and BRUNDAGE [4]. After return to control haemodynamic values, each patient received a conventional dose of a fast-release preparation of either nifedipine $(20 \mathrm{mg})$ or diltiazem $(60 \mathrm{mg})$, depending on the patients' cardiac frequency at rest (more or less than 100 beats. $\min ^{-1}$ ) and haemodynamic measurements were recorded after $1 \mathrm{~h}$. Consecutive oral doses of either nifedipine or diltiazem were then administered hourly to the patients until: 1) a positive response was observed, defined as a $>20 \%$ fall in both mean pulmonary arterial pressure and pulmonary vascular resistance, with no further decrease after one additional dose; 2) the patient experienced serious adverse effects such as shock, a decrease in systolic blood pressure $>30 \%$ relative to control value or $<90$ $\mathrm{mmHg}$, a decrease in $f \mathrm{C}<50$ beats. $\mathrm{min}^{-1} ; 3$ ) the occurrence of intolerable gastrointestinal side-effects such as vomiting, precluding further drug administration; or 4) unchanged haemodynamics after 6-8 consecutive hourly doses.

Only the patients in whom a positive response was achieved during short-term testing were considered for long- term treatment. About half of the cumulative dose of drug deemed effective was administered every $6-8$ h over $24 \mathrm{~h}$. Extended-release preparations were not used because of uncertainties in the dosage required to achieve blood levels equivalent to fast-release preparations and to limit the duration of action of the drugs in case of potential adverse effects during long-term treatment. Anticoagulant therapy with acenocoumarol or warfarin was advised in all patients, at doses needed to maintain an international normalized ratio (INR) of around 2. Repeat right-side heart catheterization was planned after at least 3 months of therapy for each patient receiving long-term treatment.

The study design was conducted as described by RIcH and BRUNDAGE [4], and each patient gave informed consent before inclusion.

\section{Statistical analysis}

All results are expressed as mean \pm SD (range). One-way analysis of variance (ANOVA) with repeated measures was performed for haemodynamic values obtained at baseline and during testing with NO and CCB. Multiple comparisons were made when the F-value was statistically significant. The Student's unpaired t-test and the Chi-squared test were performed to compare responders and nonresponders at baseline, as appropriate. A p-value $<0.05$ was taken as statistically significant.

\section{Results}

\section{Study group}

The clinical characteristics and baseline haemodynamic features of the 33 patients enrolled into the study are listed in table 1 . The mean age, sex distribution (female to male ratio $2: 1$ ), disease duration and extent of functional impairment were characteristic of PPH [17], as were the severity of haemodynamic features, with marked elevations in mean $P$ pa $(7.9 \pm 1.6 \mathrm{kPa}(59 \pm 12 \mathrm{mmHg}))$ and TPR $(3.5 \pm 1.2$ $\left.\mathrm{kPa} \cdot \mathrm{L}^{-1} \cdot \mathrm{min}^{-1} \cdot \mathrm{m}^{-2}\left(26 \pm 9 \mathrm{mmHg} \cdot \mathrm{L}^{-1} \cdot \mathrm{min}^{-1} \cdot \mathrm{m}^{-2}\right)\right)$.

Table 1. - Patient baseline clinical characteristics and haemodynamic findings

\begin{tabular}{|c|c|}
\hline Age yrs & $46 \pm 15$ \\
\hline Female/male ratio & $22 / 11$ \\
\hline \multicolumn{2}{|l|}{ Risk factors and associated conditions $n$} \\
\hline Raynaud's phenomenon & 9 \\
\hline Portal hypertension & 2 \\
\hline Family history of primary pulmonary hypertension & 1 \\
\hline Appetite suppressant use & 5 \\
\hline Human immunodeficiency virus infection & 0 \\
\hline \multicolumn{2}{|l|}{ Functional class New York Heart Association } \\
\hline I or II/III or IV n & $14 / 19$ \\
\hline \multicolumn{2}{|l|}{ Baseline haemodynamics } \\
\hline Right atrial pressure $\mathrm{mmHg}$ & $10 \pm 6$ \\
\hline Mean pulmonary artery pressure mmHg & $59 \pm 12$ \\
\hline Pulmonary artery occlusion pressure $\mathrm{mmHg}$ & $9 \pm 2$ \\
\hline Cardiac index $\mathrm{L} \cdot \mathrm{min}^{-1} \cdot \mathrm{m}^{-2}$ & $2.4 \pm 0.6$ \\
\hline Total pulmonary resistance $\mathrm{mmHg}{ }^{-1} \cdot \mathrm{L}^{-1} \cdot \mathrm{min}^{-1} \cdot \mathrm{m}^{-2}$ & $26 \pm 9$ \\
\hline Cardiac frequency beats $\cdot \min ^{-1}$ & $82 \pm 14$ \\
\hline Systemic vascular resistance $\mathrm{mmHg}{ }^{-1} \cdot \mathrm{L}^{-1} \cdot \mathrm{min}^{-1} \cdot \mathrm{m}^{-2}$ & $37 \pm 10$ \\
\hline Mixed venous oxygen saturation $\%$ & $64 \pm 10$ \\
\hline
\end{tabular}

Results are given as mean \pm SD. $1 \mathrm{mmHg}=0.133 \mathrm{kPa}$. 
Table 2. - Haemodynamic findings during acute vasodilator testing

\begin{tabular}{|c|c|c|c|c|c|c|}
\hline & \multicolumn{3}{|c|}{ Responders $(n=10)$} & \multicolumn{3}{|c|}{ Nonresponders $(n=23)$} \\
\hline & Baseline & NO & $\mathrm{CCB}$ & Baseline & NO & $\mathrm{CCB}$ \\
\hline Right atrial pressure $\mathrm{mmHg}$ & $10 \pm 5$ & $7 \pm 4 *$ & $6 \pm 4 *$ & $10 \pm 6$ & $10 \pm 6$ & $11 \pm 5$ \\
\hline Mean pulmonary artery pressure $\mathrm{mmHg}$ & $57 \pm 11$ & $39 \pm 10 * * *$ & $40 \pm 8 * * *$ & $59 \pm 12$ & $55 \pm 14$ & $55 \pm 11$ \\
\hline Pulmonary artery occlusion pressure $\mathrm{mmHg}$ & $9 \pm 2$ & ND & $\mathrm{ND}$ & $10 \pm 2$ & ND & ND \\
\hline Mean systemic arterial pressure $\mathrm{mmHg}$ & $90 \pm 11$ & $87 \pm 10$ & $80 \pm 13 *$ & $97 \pm 16$ & $97 \pm 17$ & $81 \pm 9 * * *$ \\
\hline Cardiac frequency beats $\cdot \mathrm{min}^{-1}$ & $75 \pm 14$ & $66 \pm 14 *$ & $83 \pm 17$ & $85 \pm 14$ & $83 \pm 13$ & $83 \pm 12$ \\
\hline Cardiac index $\mathrm{L} \cdot \mathrm{min}^{-1} \cdot \mathrm{m}^{-2}$ & $2.5 \pm 0.6$ & $2.8 \pm 0.6$ & $3.2 \pm 0.9 *$ & $2.4 \pm 0.6$ & $2.4 \pm 0.6$ & $2.3 \pm 0.8$ \\
\hline Total pulmonary resistance $\mathrm{mmHg} \cdot \mathrm{L}^{-1} \cdot \mathrm{min}^{-1} \cdot \mathrm{m}^{-2}$ & $25 \pm 10$ & $15 \pm 6 * * *$ & $14 \pm 6 * * *$ & $27 \pm 9$ & $24 \pm 8$ & $26 \pm 10$ \\
\hline Systemic vascular resistance $\mathrm{mmHg} \cdot \mathrm{L}^{-1} \cdot \mathrm{min}^{-1} \cdot \mathrm{m}^{-2}$ & $34 \pm 9$ & $30 \pm 6$ & $24 \pm 5 *$ & $38 \pm 9$ & $37 \pm 10$ & $32 \pm 10 *$ \\
\hline
\end{tabular}

Results are given as mean \pm SD. NO: nitric oxide; CCB: calcium-channel blockers; ND: not done. *: $\mathrm{p}<0.05$, ***: $\mathrm{p}<0.001$ (analysis of variance) compared to baseline. $1 \mathrm{mmHg}=0.133 \mathrm{kPa}$.

\section{Acute response to vasodilators}

The results of acute vasodilator challenge with $\mathrm{NO}$ and high doses of CCB are presented in table 2 .

Ten out of the 33 patients responded to $\mathrm{NO}$ with a mean decrease in $P$ pa and TPR of $32 \pm 10 \%$ (20-48) and 40 $\pm 7 \%$ (28-52), respectively. Among these patients, nine (90\%, i.e. $27 \%$ of the study population) also responded significantly to high doses of $\mathrm{CCB}$, with a mean decrease of $28 \pm 7 \%(22-43)$ in $P$ pa and $43 \pm 12 \%$ (22-61) in TPR. Responses were observed after a mean of $41 \pm 1.8$ doses (2-7) of either nifedipine $(n=7)$ or diltiazem $(n=2)$. How-
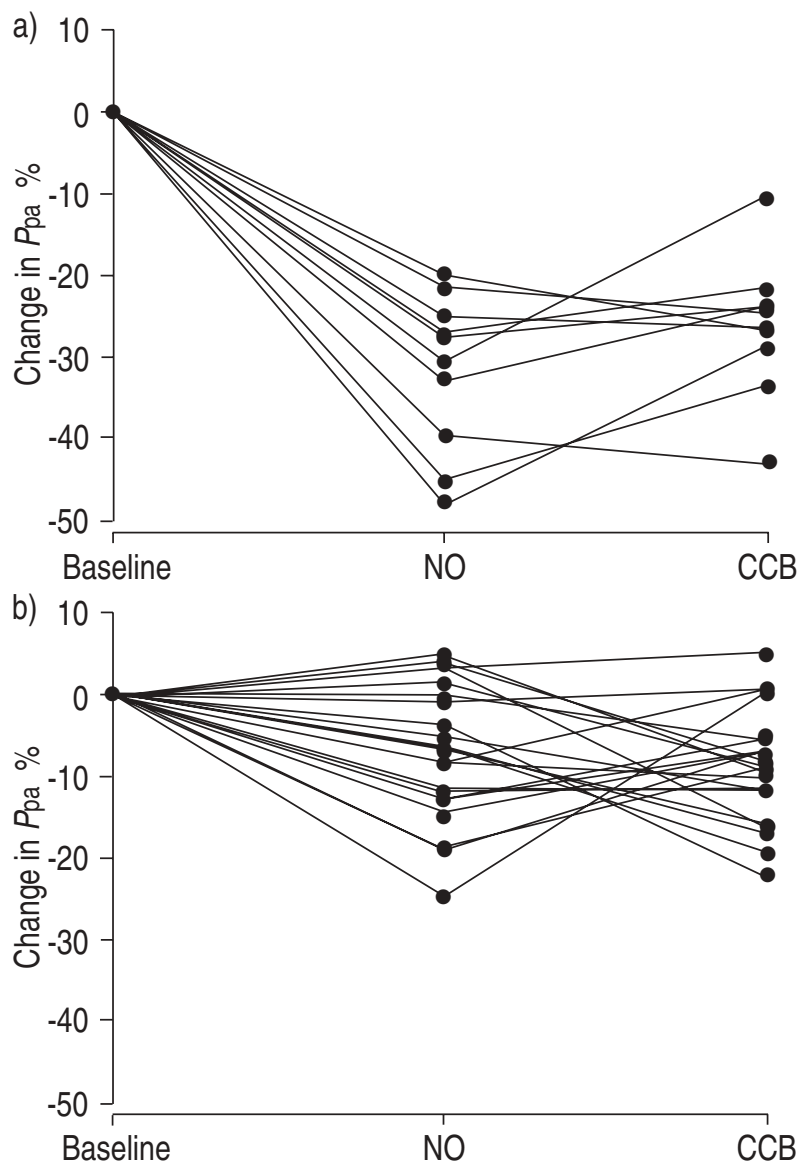

Fig. 1. - Individual change in mean pulmonary artery pressure $(P$ pa $)$ in a) responders; and b) nonresponders. One patient did not respond to a high dose of diltiazem $(360 \mathrm{mg})$ while responding to nitric oxide (NO). The two apparent responders had no significant change in total pulmonary resistance. CCB: calcium-channel blockers. ever, three patients (one-third of responders to calcium antagonists) had a significant decrease in $P$ pa and TPR as soon as $1 \mathrm{~h}$ after receiving a single test-dose of nifedipine. One patient who initially responded to NO failed to respond to diltiazem after six consecutive hourly doses. The consecutive individual changes in $P$ pa and TPR observed with $\mathrm{NO}$ and high doses of $\mathrm{CCB}$ in these patients are shown in figures $1 \mathrm{a}$ and $2 \mathrm{a}$.

The remaining patients $(\mathrm{n}=23)$ failed to respond significantly to NO, with a mean decrease in Ppa and TPR of $7 \pm 8 \%$ and $9 \pm 11 \%$, respectively. These patients also failed
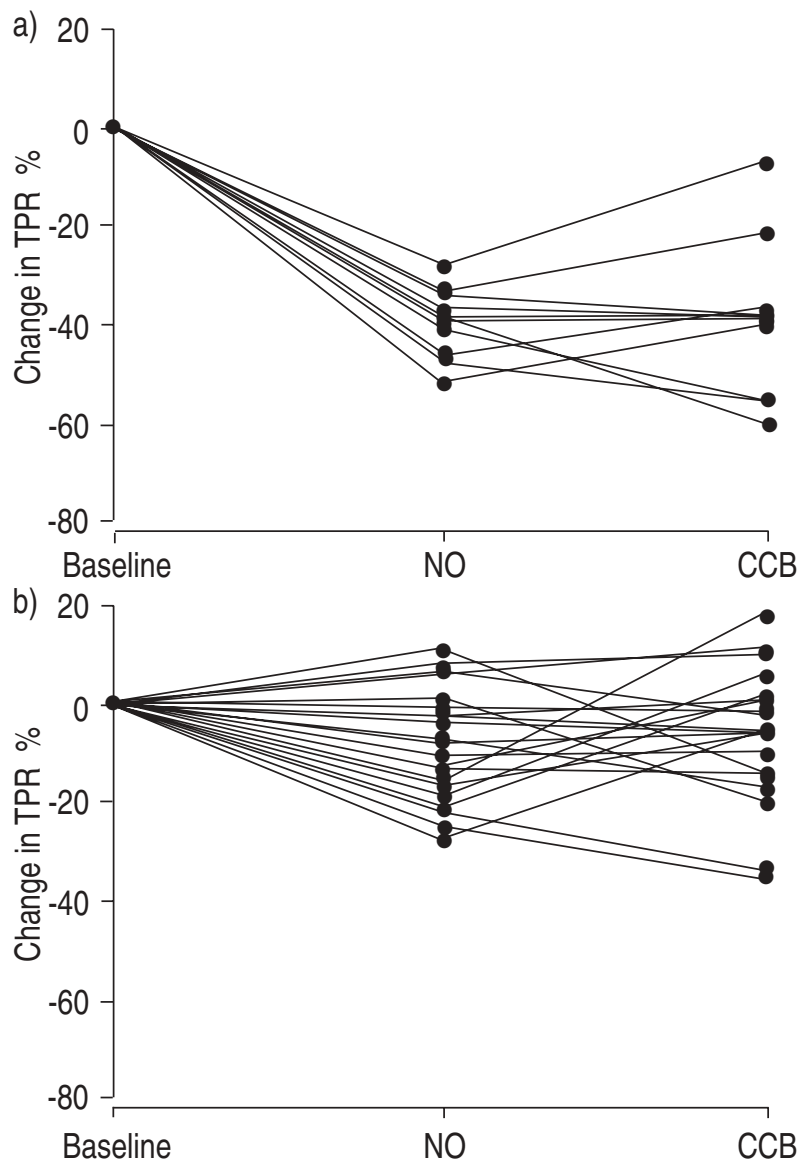

Fig. 2. - Individual change in total pulmonary resistance (TPR) in a) responders; and b) nonresponders. One patient did not respond to a high dose of diltiazem $(360 \mathrm{mg})$ while responding to nitric oxide (NO). The four patients who were apparent responders to either NO or calcium-channel blockers (CCB) had no significant change in mean pulmonary artery pressure. 
to respond to CCB. Nine had been tested with nifedipine and 14 with diltiazem. In two of them, severe systemic hypotension occurred after a single test-dose of $20 \mathrm{mg}$ nifedipine, precluding further evaluation. In the 21 remaining patients in whom larger doses (mean 5.6 2.2 , range: 2-11) were administered, the mean change in $P$ pa and TPR was $-9 \pm 7 \%(-22-+5)$ and $-6 \pm 13 \%(-35-+18)$, respectively. Individual haemodynamic changes for these patients are presented in figures $1 \mathrm{~b}$ and $2 \mathrm{~b}$. By definition, acute responders had a significant decrease in both $P$ pa and TPR. Therefore, six patients were classified as nonresponders despite an isolated decrease in Ppa or TPR (figs. $1 \mathrm{~b}$ and $2 \mathrm{~b}$ ).

No clinical or baseline haemodynamic feature were found which could have enabled us to predict which patient would have responded to vasodilators (table 3 ).

\section{Adverse events}

Inhalation of the air-NO mixture did not produce any side-effects such as systemic hypotension or cough. Ad-

Table 3. - Patient baseline clinical characteristics and haemodynamic findings in responders $(R)$ and nonresponders (NR)

\begin{tabular}{|c|c|c|}
\hline & $\begin{array}{c}\mathrm{R} \\
(\mathrm{n}=10)\end{array}$ & $\begin{array}{c}\text { NR } \\
(n=23)\end{array}$ \\
\hline Age yrs & $38 \pm 15$ & $49 \pm 14$ \\
\hline Female/male ratio & $8 / 2$ & $14 / 9$ \\
\hline Onset of symptoms months & $17 \pm 13$ & $29 \pm 26$ \\
\hline \multicolumn{3}{|l|}{ Functional class NYHA } \\
\hline I or II/III or IV $n$ & $4 / 6$ & $10 / 13$ \\
\hline \multicolumn{3}{|l|}{ Baseline haemodynamics } \\
\hline Right atrial pressure $\mathrm{mmHg}$ & $10 \pm 5$ & $10 \pm 6$ \\
\hline Mean pulmonary artery pressure $\mathrm{mmHg}$ & $57 \pm 11$ & $59 \pm 12$ \\
\hline Pulmonary artery occlusion pressure $\mathrm{mmHg}$ & $9 \pm 2$ & $10 \pm 2$ \\
\hline Mean systemic arterial pressure $\mathrm{mmHg}$ & $90 \pm 11$ & $97 \pm 16$ \\
\hline Cardiac frequency beats $\cdot \mathrm{min}^{-1}$ & $75 \pm 14$ & $85 \pm 14$ \\
\hline Cardiac index $\mathrm{L} \cdot \mathrm{min}^{-1} \cdot \mathrm{m}^{-2}$ & $2.5 \pm 0.6$ & $2.4 \pm 0.6$ \\
\hline $\begin{array}{l}\text { Total pulmonary resistance } \\
\mathrm{mmHg} \cdot \mathrm{L}^{-1} \cdot \mathrm{min}^{-1} \cdot \mathrm{m}^{-2}\end{array}$ & $25 \pm 10$ & $27 \pm 9$ \\
\hline $\begin{array}{l}\text { Systemic vascular resistance } \\
\mathrm{mmHg} \cdot \mathrm{L}^{-1} \cdot \mathrm{min}^{-1} \cdot \mathrm{m}^{-2}\end{array}$ & $34 \pm 9$ & $38 \pm 9$ \\
\hline Mixed venous oxygen saturation & $67 \pm 10$ & $59 \pm 10$ \\
\hline
\end{tabular}

Results are given as mean \pm SD. NYHA: New York Heart Association. There were no significant differences between the groups. $1 \mathrm{mmHg}=0.133 \mathrm{kPa}$.
Table 4. - Adverse events with high doses of calciumchannel blockers

\begin{tabular}{ll}
\hline Responders $(\mathrm{n}=9)$ & Nonresponders $(\mathrm{n}=24)$ \\
No adverse & One death, 12 h after completion of the \\
reaction & protocol \\
& Eight severe adverse events: \\
& shock $(\mathrm{n}=1)$ \\
& severe systemic hypotension $(\mathrm{n}=5)$ \\
& vomiting $(\mathrm{n}=2)$ \\
& Five major adverse events: \\
& nausea $(\mathrm{n}=3)$ \\
& headache $(\mathrm{n}=2)$ \\
\hline
\end{tabular}

verse events that occurred during short-term testing with high-dose CCB are listed in table 4. Responders did not complain of any discomfort, nausea, headache or other more severe adverse reactions, whereas one third (eight patients) of the nonresponders presented severe adverse reactions including shock $(n=1)$, prolonged systemic hypotension $(\mathrm{n}=5)$ requiring fluid loading and inotropic support with dobutamine for $>24 \mathrm{~h}$, and two patients suffered from severe vomiting precluding further drug testing. One patient died suddenly $12 \mathrm{~h}$ after completion of the vasodilator challenge, although no adverse event was reported during oral diltiazem challenge (total dose: $360 \mathrm{mg}$ ). Five other nonresponders had minor side-effects such as nausea and headache. The high incidence of severe adverse events encountered led us to interrupt the study.

\section{Long-term response to calcium-channel blockers}

Long-term therapy with high doses of CCB was restricted to the nine short-term responders, with either nifedipine in seven or diltiazem in two subjects. Eight of these patients returned for haemodynamic evaluation after $13 \pm 4$ months (range 7-19) of treatment with CCB (table 5). Six patients (18\%) had a sustained and major chronic vasodilator effect, but two failed to respond to long-term treatment. The remaining patient died 4 months after the treatment with nifedipine.

\section{Discussion}

In patients with $\mathrm{PPH}$, the question of the overall efficacy of administering vasodilators is still of concern, as is

Table 5. - Long-term response to high doses of calcium-channel blockers (CCB) in responders

\begin{tabular}{|c|c|c|c|c|c|c|c|c|c|c|c|}
\hline \multirow{2}{*}{$\begin{array}{l}\text { Patient } \\
\text { no. }\end{array}$} & \multicolumn{2}{|c|}{ Baseline } & \multicolumn{3}{|c|}{ Acute testing } & \multicolumn{3}{|c|}{3 months } & \multicolumn{3}{|c|}{ Last news* } \\
\hline & $P$ pa & TPR & $\begin{array}{c}\mathrm{CCB} \\
\mathrm{mg}\end{array}$ & $P$ pa & TPR & $\begin{array}{c}\text { CCB } \\
\mathrm{mg} \cdot \text { day }^{-1}\end{array}$ & $P_{\mathrm{pa}}$ & TPR & $\begin{array}{c}\text { CCB } \\
\mathrm{mg} \cdot \text { day }^{-1}\end{array}$ & $P$ pa & TPR \\
\hline 1 & 57 & 24.4 & DTZ 360 & 43 & 14.4 & DTZ 720 & 41 & 9.4 & DTZ 720 & 28 & 8.1 \\
\hline 2 & 68 & 23.1 & NIF 140 & 48 & 10.1 & - & ND & $\mathrm{ND}$ & NIF 120 & 30 & 10.9 \\
\hline 3 & 42 & 12.8 & NIF 80 & 28 & 8.0 & NIF 120 & 27 & 7.0 & DTZ $360^{+}$ & 27 & 7.9 \\
\hline 4 & 62 & 23.5 & NIF 40 & 35 & 10.3 & NIF 60 & 46 & 15.6 & DTZ $360^{+}$ & 47 & 17.8 \\
\hline 5 & 45 & 18.6 & NIF 80 & 34 & 11.6 & NIF 60 & 47 & 17.3 & DTZ $360^{+}$ & 56 & 21.1 \\
\hline 6 & 70 & 44.8 & NIF 60 & 51 & 17.5 & NIF 160 & 44 & 12.9 & NIF 160 & 46 & 12.0 \\
\hline 7 & 59 & 30.0 & NIF 60 & 43 & 18.2 & - & ND & ND & NIF 180 & 54 & 19.7 \\
\hline 8 & 39 & 13.0 & NIF 40 & 30 & 8.0 & NIF 90 & 41 & 13.2 & DTZ $360^{+}$ & 48 & 14.2 \\
\hline 9 & 60 & 32.4 & DTZ 360 & 45 & 25.4 & - & $\mathrm{ND}$ & $\mathrm{ND}$ & - & $\mathrm{ND}$ & $\mathrm{ND}$ \\
\hline
\end{tabular}

$P_{\text {pa: }}$ mean pulmonary artery pressure $(\mathrm{mmHg})$; TPR: total pulmonary resistance $\left(\mathrm{mmHg} \cdot \mathrm{L}^{-1} \cdot \mathrm{min}^{-1} \cdot \mathrm{m}^{-2}\right)$; DTZ: diltiazem; NIF: nifedipine; $\mathrm{ND}$ : not done. $1 \mathrm{mmHg}=0.133 \mathrm{kPa}$. *: At $13 \pm 4$ months (range 7-19). +: In all patients, adverse events such as lower limbs oedema occurred with nifedipine, leading to the substitution with diltiazem. 


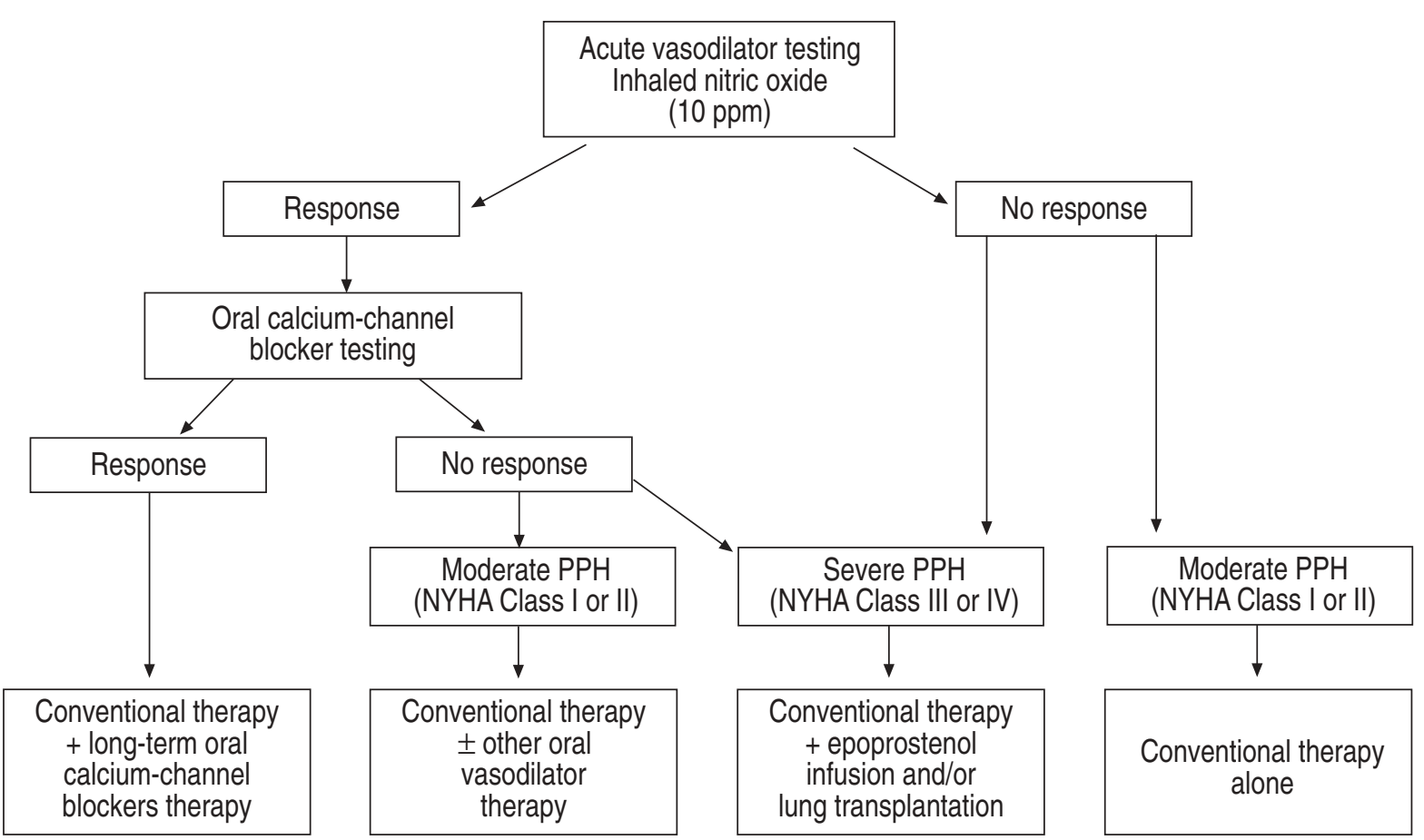

Fig. 3. - Current protocol for the therapeutic approach to primary pulmonary hypertension (PPH) (South-Paris University). Vasodilator response is defined by a fall in both mean pulmonary pressure and total pulmonary resistance by $>20 \%$. Conventional therapy includes oral anticoagulation with diuretics and supplemental oxygen if necessary. Epoprostenol infusion is used as an alternative or a bridge to transplantation. Other oral vasodilators include nitroglycerine, phentolamine and hydralazine. NYHA: New York Heart Association; ppm: parts per million.

the method of safely identifying those patients who may benefit from long-term treatment $[18,19]$. It is generally accepted that the initial response to acute vasodilator testing accurately identifies patients with PPH who are likely to respond to chronic oral treatment [3]. Currently, the most widely used drugs for long-term therapy are the CCB nifedipine and diltiazem $[3,6]$.

The main result of our study was to demonstrate that serious adverse events were frequently observed during acute vasodilator challenge with oral CCB (38\%). Interestingly, these adverse events, such as vomiting, hypotension, or shock, were only observed in nonresponders to CCB. The importance of these adverse reactions, which may be life-threatening, led us to interrupt the study. Significant side-effects during acute testing with $\mathrm{CCB}$ have been previously described by other investigators [9, 10], including a case of sudden death following the administration of a single dose of nifedipine in a patient with PPH [8]. This contrasted with the absence of severe side-effects reported in the main study published by Rich et al. [6] on acute testing with high-doses of CCB. There is no clear explanation for these distinct results. Indeed, the study design for acute vasodilator testing was identical in the present study and the report by Rich et al. [6]. The patients enrolled in the present study had severe pulmonary hypertension (table 1) with comparable clinical and haemodynamic characteristics to the patients reported by RICH $e t$ al. [6]. The average dose of CCB given to achieve the maximal pulmonary vasodilatation was the same in the two studies. The proportion of responders was identical in both studies $(27 \%)$, with a similar magnitude in the pulmonary vasodilator response.

Another important finding of the present study was the demonstration that during the initial evaluation of a large number of consecutive patients with PPH, NO inhalation induced a comparable individual pulmonary vasodilatation to that achieved with high doses of oral CCB. Acute vasodilator testing with inhaled $\mathrm{NO}$ had a sensitivity of $90 \%$ and a specificity of $100 \%$ in detecting a short-term pulmonary vasodilator response to oral CCB. The acute pulmonary vasodilation with inhaled NO, a selective pulmonary vasodilator, was obtained without any adverse event, as we reported previously [12]. Thus, NO can accurately and safely detect those patients with $\mathrm{PPH}$ who may benefit from long-term treatment with oral CCB (fig. 3).

In conclusion, in patients with primary pulmonary hypertension, acute testing with oral calcium channel blockers can induce significant adverse reactions, especially in patients who fail to respond to these agents. Therefore, during initial acute haemodynamic evaluation, inhaled nitric oxide, or another short-acting agent, should be used as a first-line vasodilator agent in screening pulmonary vascular responsiveness. Oral calcium-channel blockers should not be used as a screening agent for pulmonary vascular responsiveness in patients with primary pulmonary hypertension. The chronic use of calcium-channel blockers should be restricted to primary pulmonary hypertension patients who respond acutely to inhaled nitric oxide.

Acknowledgements: The authors wish to dedicate this report to F. Brenot ${ }^{\dagger}(1955-1996)$.

\section{References}

1. Weir EK, Rubin LJ, Ayres SM, et al. The acute administration of vasodilators in primary pulmonary hypertension: experience from the National Institutes of Health 
Registry on Primary Pulmonary Hypertension. Am Rev Respir Dis 1989; 140: 1623-1630.

2. Weir EK. Acute vasodilator testing and pharmacological treatment of primary pulmonary hypertension. In: Fishman AP, ed. The pulmonary circulation: normal and abnormal. Mechanisms, management and the national registry. Philadelphia, PA, University of Pennsylvania Press 1990; pp. 485-499.

3. Rubin LJ. Primary pulmonary hypertension. $N$ Engl $J$ Med 1997; 336: 111-117.

4. Rich S, Brundage BH. High-dose calcium channel-blocking therapy for primary pulmonary hypertension: evidence for long-term reduction in pulmonary arterial pressure and regression of right ventricular hypertrophy. Circulation 1987; 76: 135-141.

5. Rich S, Kaufmann E. High dose titration of calcium channel blocking agents for primary pulmonary hypertension: guidelines for short-term drug testing. J Am Coll Cardiol 1991; 18: 1323-1327.

6. Rich S, Kaufmann E, Levy PS. The effect of high doses of calcium-channel blockers on survival in primary pulmonary hypertension. N Engl J Med 1992; 327: 76-81.

7. Hoeper MM, Wilke T, Welte T, Breuer HWM, Wagner TOF. How effective is the treatment with high-dose nifedipine for primary pulmonary hypertension? Semin Respir Crit Care Med 1994; 15: 490-494.

8. Partanen J, Nieminen MS, Luomanmaki K. Death in a patient with primary pulmonary hypertension after $20 \mathrm{mg}$ of nifedipine. N Engl J Med 1993; 329: 812.

9. Farber HW, Karlinskz JB, Faling LJ. Fatal outcome following nifedipine for primary pulmonary hypertension. Chest 1983; 83: 708-709.

10. Aromatorio GJ, Uretsky BF, Reddy PS. Hypotension and sinus arrest with nifedipine in pulmonary hypertension. Chest 1985; 87: 265-267.
11. Raffy O, Azarian R, Brenot F, et al. Clinical significance of the pulmonary vasodilator response during short-term testing with prostacyclin in primary pulmonary hypertension. Circulation 1996; 93: 484-488.

12. Sitbon O, Brenot F, Denjean A, et al. Inhaled nitric oxide as a screening vasodilator agent in primary pulmonary hypertension. A dose-response study and comparison with prostacyclin. Am J Respir Crit Care Med 1995; 151: 384-389.

13. Simonneau G, Herve P, Petitpretz P, et al. Detection of a reversible component in primary pulmonary hypertension: value of prostacyclin acute infusion. Am Rev Respir Dis 1986; 133: A223.

14. Palevsky HI, Long W, Crow J, Fishman AP. Prostacyclin and acetylcholine as screening agents for acute pulmonary vasodilator responsiveness in primary pulmonary hypertension. Circulation 1990; 82: 2018-2026.

15. Rubin LJ, Groves BM, Reeves JT, Frosolono M, Handel F, Cato AE. Prostacyclin-induced acute pulmonary vasodilation in primary pulmonary hypertension. Circulation 1982; 66: 334-338.

16. Pepke-Zaba J, Higenbottam TW, Dinh-Xuan AT, Stone $\mathrm{D}$, Wallwork J. Inhaled nitric oxide as a cause of selective pulmonary vasodilatation in pulmonary hypertension. Lancet 1991; 338: 1173-1174.

17. Rich S, Dantzker DR, Ayres SM, et al. Primary pulmonary hypertension: a national prospective study. Ann Intern Med 1987; 107: 216-223.

18. Packer M. Is it ethical to administer vasodilator drugs in patients with primary pulmonary hypertension? Chest 1989; 95: 1173-1175.

19. Reeves JT, Groves BM, Turkevich D. The case for treatment of selected patients with primary pulmonary hypertension. Am Rev Respir Dis 1986; 134: 342-346. 